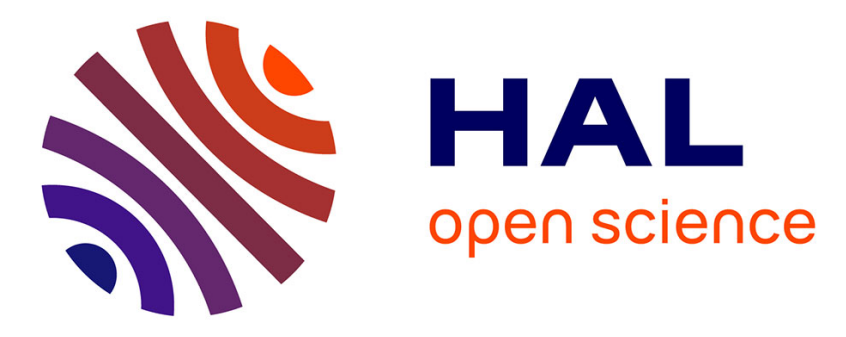

\title{
Investigating how children produce rotation and pointing movements when they learn to write letters
}

Laurence Seraphin-Thibon, Guillaume Barbier, Coriandre Emmanuel Vilain, Thomas R. Sawallis, Silvain Gerber, Sonia Kandel

\section{- To cite this version:}

Laurence Seraphin-Thibon, Guillaume Barbier, Coriandre Emmanuel Vilain, Thomas R. Sawallis, Silvain Gerber, et al.. Investigating how children produce rotation and pointing movements when they learn to write letters. Human Movement Science, 2018, 65, pp.15-29. 10.1016/j.humov.2018.04.008 . hal-01983489

\section{HAL Id: hal-01983489 \\ https://hal.science/hal-01983489}

Submitted on 25 Oct 2021

HAL is a multi-disciplinary open access archive for the deposit and dissemination of scientific research documents, whether they are published or not. The documents may come from teaching and research institutions in France or abroad, or from public or private research centers.
L'archive ouverte pluridisciplinaire HAL, est destinée au dépôt et à la diffusion de documents scientifiques de niveau recherche, publiés ou non, émanant des établissements d'enseignement et de recherche français ou étrangers, des laboratoires publics ou privés.

\section{(ㄷ)(1) $\$$}

Distributed under a Creative Commons Attribution - NonCommerciall 4.0 International 
Investigating how children produce rotation and pointing movements when they learn to write letters

Laurence Séraphin Thibon ${ }^{1}$, Guillaume Barbier ${ }^{1}$, Coriandre Vilain ${ }^{1}$, Thomas R. Sawallis ${ }^{2}$, Silvain Gerber ${ }^{1} \&$ Sonia Kandel ${ }^{1}$

${ }^{1}$ Univ. Grenoble Alpes, GIPSA-lab (CNRS UMR 5216), Grenoble, France ${ }^{2}$ University of Alabama, New College, Tuscaloosa, AL, USA

Corresponding author:

Sonia Kandel

Univ. Grenoble Alpes

GIPSA-lab (CNRS UMR 5216)

11 rue des Mathématiques - Grenoble Campus BP46

38402 Saint Martin d'Hères - Cedex

France

Phone: +33476 574959

Email: Sonia.Kandel@univ-grenoble-alpes.fr 


\begin{abstract}
How do children learn to write letters? During writing acquisition, some letters may be more difficult to produce than others because certain movement sequences require more precise motor control (e.g., the rotation that produces curved lines like in letter $\mathrm{O}$ or the pointing movement to trace the horizontal bar of a T). Children of ages 6-10 $(\mathrm{N}=108)$ wrote sequences of upper-case letters on a digitizer. They varied in the number of pointing and rotation movements. The data revealed that these movements required compensatory strategies in specific kinematic variables. For pointing movements there was a duration decrease that was compensated by an increase in in-air movement time. Rotation movements were produced with low maximal velocity but high minimal velocity. At all ages there is a global tendency to keep stability in the tempo of writing: pointing movements exhibited a duration trade-off whereas rotation movements required a trade-off on maximal and minimal velocity. The acquisition of letter writing took place between ages 6 and 7. At age 8 the children shifted focus to improving movement control. Writing automation was achieved around age 10 when the children controlled movement duration and fluency. This lead to a significant increase in writing speed.
\end{abstract}

Keywords: handwriting; children; letters; rotation movements; pointing movements

Short title: Rotation and pointing movements in letter production 
Introduction

Children spend at least half of their school time in activities involving writing or fine motor control (Marr, Cermak, Cohn \& Henderson, 2003; Santangelo \& Graham, 2016). Writing is a complex task that involves the acquisition of different kinds of motor and perceptual skills. Children must learn how to produce the movements that generate the appropriate letters. In addition, they have to learn how to process the visual and kinesthetic sensory information arising from their movements (Bard, Hay \& Fleury, 1990; Olive \& Piolat, 2002; Feder \& Majnemer, 2007; Danna \& Velay, 2015). They also have to compute specific calculations on spatial parameters to produce the correct letter shapes. At the beginning of handwriting acquisition, the children start learning letter production by following a sort of "grammar of action" (Bruner, 1971; Goodnow \& Levine, 1973; Bara \& Bonneton-Botte, 2015; SéraphinThibon, Gerber \& Kandel, 2017). This constitutes a set of rules that specifies procedural knowledge on how to write the letters. The rules define where to start writing each letter and the direction of the following strokes that are needed to write a given character (e.g., "start at a leftmost and topmost point", "draw vertical lines from top to bottom", "draw horizontal lines from left to right"). The rules that the children learn at school are hierarchical. Some rules have to be applied before others. For example, to write a T, first we apply "draw vertical lines from top to bottom" and then "draw horizontal lines from left to right".

This hierarchy has a certain number of implications regarding the difficulty producing certain letters. For example, the letter $L$ is composed of two straight lines. By following the rules, children will produce the vertical line from top to bottom and then trace the horizontal line from left to right. This left to right movement is continuous with the vertical line and is done without lifting the pen. Letter $\mathrm{T}$ also consists of two straight lines, but to produce the horizontal line on the top, one has to perform a pen lift and then a pointing movement to trace 
the horizontal line from left to right. The pointing movement renders letter T more cognitively demanding than letter L. Indeed, there is a supplementary movement. In addition, the child has to visualize the position of the target. This visualization process is not the same for all the letters requiring pointing movements. For example, the target for the horizontal movement to produce letter $\mathrm{T}$ is different than for letter $\mathrm{A}$. Hence, some letters may be more difficult to produce than others because certain movement sequences involve finer motor control and/or visuo-spatial coordination. During our interactions with children just starting to learn to write, we observed that the letters requiring pointing movements such as the ones we have to execute when producing the horizontal bar on a $T$ seem particularly demanding. At the beginning of the acquisition period the children also have difficulties with rotations to produce curved lines like in an $\mathrm{O}$. Figure 1 presents examples of upper-case letters $\mathrm{O}$ and $\mathrm{T}$ produced by a 6 year-old child at the beginning of $1^{\text {st }}$ grade.

\section{$<$ Figure $1>$}

To produce $T$, there is an initial movement that traces a straight line from top to bottom. Then, there is a pointing movement that takes the pen tip to the location where the following line has to be produced. Finally, letter $\mathrm{T}$ is finished with a horizontal left to right straight line. This task may be cognitively demanding because reaching the correct "target" i.e., where the pen has to touch the surface again- requires programming a pen lift and calculating the exact location in space to start writing again. On the left part of Figure 1, one can observe that the child "missed" the target because the two lines do not touch each other and the vertical line is not centered with respect to the horizontal line. On the right side of Figure 1, it is clear that the child had difficulties producing the rotation movement of the letter O. The curved line is very irregular even if legible. In addition, the letter $O$ is generally a closed circle, but here the production is rather a vertical ellipse whose beginning and end do 
not join. Given these difficulties, the goal of the present study was to gain more understanding on the impact of pointing and rotation movements on letter production at the beginning of writing acquisition. Elementary school children produced letter sequences on a digitizer so several kinematic measures could be examined. The sequences varied in the number of pointing and rotation movements.

\subsection{Learning how to write letters}

This research was conducted in France with a Latin alphabet. In France, writing is formally taught in $1^{\text {st }}$ grade, at the beginning of elementary school, when the children are around 5-6 years-old. When children start $1^{\text {st }}$ grade, they already know how to use the hand-arm system in many different kinds of everyday tasks, like eating or brushing their teeth. They also know how to use pens, markers and pencils to draw. Thus, when starting elementary school the children must learn to further specialize their hand-arm system for writing. Learning to write letters involves the integration of a series of skills and it takes several years to be proficient in all of them (Chartrel \& Vinter, 2004). Therefore, learning how to write should be considered within the framework of general motor learning and maturation. Motor maturation allows children to coordinate the proximal and distal articulations (de Ajuriaguerra et al., 1964) but as they are starting to learn to write they mainly use their proximal articulations. Their movements are impulsive. This is why the amplitude of their movements is generally quite large and lacks precision. With motor maturation, the children will be able to control the distal aspects of movement production and will therefore control their movements with more precision. The amplitude of the movements will decrease, while velocity and fluency will increase (Meulenbroek \& Van Galen, 1988; Mojet, 1991; Zesiger, 1995). 
General motor learning also requires the elaboration of motor programs (Halsband \& Lange, 2006). The first motor programs for letter writing are generated when the teachers introduce the rules of the "grammar of action". First, they present the model of the letter so that the children know what shape they have to reproduce. Next they indicate where to start the first stroke, followed by the stroke direction. This process will repeat in correct stroke order until all the strokes of the letter are written. Like any motor learning situation, at the beginning the movements are produced slowly and lack smoothness or fluency. At this stage the children are still elaborating the links between sensory information and the resulting movements (Wolpert, Ghahramani \& Jordan, 1995). The objective of this intense visual and kinesthetic sensory control is to determine which motor patterns generate the letter shapes that best comply with the geometrical parameters of the model. This process is very demanding in both attentional resources (Atkinson, 1989; Petersen, Corbetta, Miezin \& Shulman, 1994; Shadmehr \& Mussa-Ivaldi, 1994) and working memory (Deiber et al., 1997). With practice, the information on letter shape, stroke order and direction are memorized with progressively increasing detail. This information enriches the content of the motor programs. When the motor programs contain all the procedural information needed to execute a given letter, they are considered stable. They are stored in a long-term motor memory. When the child has to produce a given letter, he/she activates the corresponding motor program to retrieve the information on letter shape, stroke order and direction. This is done in a feed-forward manner, on the basis of previous knowledge. This feed-forward strategy decreases the need for sensory control and attentional processes (Meulenbroek \& van Galen, 1986, 1988, 1989a). The control of the writing movements becomes more ballistic, rendering letter production faster and more precise. Automation is achieved when each letter is retrieved as a learned action and has a stable motor program (Halsband \& Lange, 2006). 
An important aspect of letter acquisition -as for motor learning in general- is that the components of motor program elaboration are learnt through different kinds of processes. Certain components are acquired explicitly and others implicitly (Halsband \& Lange, 2006). When the teachers instruct the children to follow rules for letter production, motor learning is explicit. Rules indicating movement onset and stroke direction are explicit because the child is conscious of having to respect them to write correctly. In the present study, we investigated components of motor learning that are not taught explicitly but are essential for letter production. These implicit components are related to the execution of pointing and rotation movements. There is no information on explicit instruction of pointing and rotation movements in the French teachers' manuals (see Ministère de l'Education Nationale, EduSCOL, 2015). This is surprising because as we mentioned earlier, these movements may be more cognitively demanding than, for instance, producing simple straight lines from top to bottom. The children learn how to execute pointing and rotation movements implicitly in drawing activities during the three years of kindergarten. Learning is mostly based on trial and error strategies. To our knowledge, there are very few studies investigating pointing and rotation movements in handwriting and even fewer with a developmental approach.

\subsection{Pointing movements in letter production}

Pointing movements are not specific to writing. However, many letters of most writing systems and styles require pointing movements (Meulenbroek \& van Galen, 1986; Wann, 1986). In the Latin alphabet, producing upper-case letters and writing in lower-case print style requires many pointing movements to put all the lines together (e.g., make the two lines of an $h$ touch each other), finish certain letters (e.g., putting the dot on letter $j$ ) and passing from the end of a letter to the onset of the following one. The reason why they are called pointing 
movements is that their objective is to reach a specific target or spatial location. To do so, there is a moment in which the pen is in the air and does not touch the paper. In this sense, the movement to start writing a letter, its onset, is also a pointing movement. In this study we did not consider letter onset movements as pointing movements. The pointing movements we studied are the in-air movements that are done within a letter after the initial stroke. They are movements that produce the subsequent strokes to finish a letter. Pointing movements in adults are ballistic and therefore very fast (Teulings, 1996). One of the reasons for the speed difference with other writing movements is that the hand is in the air. There is no friction with the paper during its production, so there is no physical resistance to slow down the movement. Pointing movements are produced with almost no sensory feedback. For the target to be reached correctly, there has to be a thorough visuo-spatial analysis of its location. This means that before executing the in-air movement we also have to integrate the information resulting from visual and proprioceptive feedback. This requires coordination from several distinct processing levels. Therefore, it should be cognitively demanding when the children starting learning to write.

Meulenbroek and van Galen (1988) conducted an experiment in which the children had to write the 26 cursive letters of the alphabet on a digitizer. The kinematic data indicated that the children of ages 5-6 tend to write with sequences of ballistic movements. Since feedback is limited the probability of missing the location of the target is high. Although the children try to follow the grammar of action for letter production, movement control lacks accuracy. This is probably the reason why the child writing the letter in Figure 1 did not reach the target correctly when he did the pointing movement. Then there is a transition around ages 6-7, where the writing is modulated by close sensory feedback. The children gain in accuracy because they generate sensory-motor links between their movements and the shape of the models they have to reproduce. Around ages 8-9, once the child knows which is the correct 
movement to produce the correct shape, the movements become more ballistic but also integrate sensory feedback. This pattern of results indicates that the involvement of sensory feedback changes as the children practice writing.

There are very few developmental studies investigating the role of sensory feedback during movement control of pointing movements. Ferrel, Bard and Fleury (2001) manipulated visual feedback in an experiment where children from 6 to 11 years old and adults had to execute pointing movements. The visual feedback was provided by a computer screen located in front of the participant. The age 6 children had serious difficulties in reaching the targets when they could not see their hand directly and when the angle of the position of the target was modified. Visual feedback was clearly necessary for programming the pointing movements. The 8 year-old children instead produced fewer pointing errors. They could program their movements even when the feedback was modified spatially. The results suggest that the role of visual feedback during movement programming evolves as the children learn to represent their pointing movements in space. Another study by Pellizzer and Hauert (1996) on spatial localization supports the idea of a major change for visual and motor coordination at age 8 . Children from ages 6 to 10 had to point with their hand to a target that varied in eccentricity. The results revealed that at age 8 spatial localization processes change. This has an impact on the way visual feedback information is translated into motor representations. The authors suggested that this could be due to the maturation of the left hemisphere.

For writing, research by Klein, Guiltner, Sollereder and Cui (2011) provided empirical evidence on the importance of visual feedback in a developmental perspective. Children aged 8 to 11 had to do a copying task. The results revealed that visual information accounted for $26 \%$ of the variance of writing speed. According to Marquardt, Gentz and Mai $(1996,1999)$ visual feedback is particularly useful to adjust the writing movements to spatial constraints such as letter size. For Grossberg and Paine (2000) feedback is of course essential to regulate 
the movement amplitude but they also point to an important role of visual information for controlling the orientation of the movements. This is in line with another experiment done with children of ages 8-10 and adults indicating that the absence of visual feedback results in a performance decrease. There was a decline on all kinematic measures (Chartrel \& Vinter, 2006). In sum, visual feedback regulates movement control in tasks involving pointing movements as well as writing. This could explain why having to produce letters with many pointing movements is so demanding in cognitive resources.

\subsection{Rotation movements in letter production}

All writing systems involve curved lines. Some writing styles like cursive handwriting, use more curved lines than others because the writing is continuous and there are hardly any spaces between letters. In cursive handwriting, the curves are generally loops and sequences of ellipses. There are few straight lines. Circles are also infrequent because when they are produced at high speed the bio-mechanical constraints of the hand make them more oval-like (Dounskaia, Van Gemmert, \& Stelmach, 2000; Danna, Enderli, Athènes \& Zanone, 2012). In addition, the letters are connected to one another by connection strokes that are short curved lines. To write letters made of curved lines we have to produce rotation movements with the fingers, the wrist or both. These rotations have to be very precise, so that the rounding gesture is smooth, regular and traces a trajectory with a satisfactory radius of curvature. The number of studies on motor control for the production of curved lines is extremely limited.

Research on drawing and writing has indicated that producing curved lines requires a decrease in velocity. We have known since Binet and Courtier (1893) that movement speed increases when tracing straight lines and decreases when producing curved lines. The reason for this velocity decrease is related to the bio-mechanic constraints of motor production. This 
functional relation between spatial and motor constraints has been studied extensively and is known through its mathematical description as the $2 / 3$ power law (e.g., Viviani \& Terzuolo, 1982). It stipulates that the tangential velocity of the writing and drawing movements is a function of the radius of curvature of the figure. Although writing movements do not comply perfectly with the $2 / 3$ power law (Thomassen \& Teulings, 1985) and it is not functional before age 13 (Viviani \& Schneider, 1991), simple observation of writing behavior clearly shows that children slow down their movements when producing letters with curved lines.

Some studies related to the execution of curved lines concerned circle production (Van Sommers, 1984; Meulenbroek, Vinter, \& Mounoud, 1993; Vinter, 1994; Rueckriegel et al., 2008). At the beginning the children start tracing circles from the bottom. Then with practice, the onset of the circles will be located on the top. The consequence of this change in onset location switches the rotation from clock-wise to counter-clock-wise. The rule the children are taught at school is to start writing letter $\mathrm{O}$ in the 12 o'clock position with a counter-clock-wise rotation. These changes in onset location and rotation direction require different ways of coordinating the fingers and the wrist. This may also explain why writing curved lines slows down the movement with respect to writing straight lines.

Bernstein (1967) proposed a motor learning model based on degrees of freedom and their coordination (i.e., muscle synergies). Kelso (1982) further developed this theory of movement by indicating that muscles and joints do not work in isolation but in coordinated groups. On this basis, Grossberg and Paine (2000) proposed a model for learning to produce curved movements. Each movement is the result of a motor program that is controlled by a planning vector. These vectors control the speed for a whole sequence of curves. At the beginning of the acquisition process, children produce many movements that are segmented and lack fluency. They go back and forth between the position of their hand and the location of the point they have to reach. This process is repeated multiple times so that the children can 
readjust the planning vectors until they learn to produce the sequences of curves correctly. This kind of processing could be applied to writing but should be taken with caution since the children differentiate between drawing and writing very early, before even knowing how to read and write (Lavine, 1977; Goodnow, 1986; Karmiloff-Smith, 1992; Brenneman, Massey , Machado \& Gelman, 1996; Adi-Japha \& Freeman, 2001; Tolchinsky-Landsmann, 2003).

In the present study we examined the impact of pointing and rotation movements on letter production during writing acquisition. The children wrote pseudo-word letter sequences on a digitizer. The sequences were presented in upper-case letters and the children had to reproduce them in upper-case as well. The reason for this instruction was to maximize the number of pointing movements during letter production. Upper-case letters and print require many pointing movements whereas the continuous character of cursive handwriting minimizes them. In French kindergartens the children are informally introduced to writing with print upper-case letters. Then, in $1^{\text {st }}$ grade (around age 6) they are formally instructed to write in cursive style. There is no instruction for writing script lower-case letters. Therefore, with an upper-case letter writing task we were sure that all the children were familiar with the target models and how to execute them, even the younger ones.

Method

\section{Participants}

A total of 108 children participated in the experiment. There were 256 -year-olds (mean $=6 ; 6$, $\mathrm{SD}=0 ; 2), 23$ 7-year-olds (mean $=7 ; 4, \mathrm{SD}=0 ; 3), 19$ 8-year-olds $($ mean $=8 ; 6, \mathrm{SD}=0 ; 5), 19$ 9-year-olds (mean $=9 ; 8, \mathrm{SD}=0 ; 4)$ and 22 10-year-olds $($ mean $=10 ; 9, \mathrm{SD}=0 ; 3)$. They were all right-handed and had normal or corrected-to-normal vision. They were native French- 
speakers and attended a public elementary school in the suburbs of Grenoble. Reading and writing skills were taught from the beginning of the school year (i.e., September) in $1^{\text {st }}$ grade (age 6). The experiment took place in March so the $1^{\text {st }}$ graders could do the task correctly. All the children attended the grade that was expected for their age. Any children with motor or hearing impairments, learning disabilities, brain or behavioral problems were excluded from the study. We required parental written consent for participation. This study respected all the ethical guidelines of the Grenoble ethical committee (CERNI authorization 2015-11-10-75).

\section{Materials}

The stimuli consisted of 24 pseudo-words written in upper-case letters. We chose to use the Calibri upper-case font for this experiment because we thought it was the font that complied the most to the upper-case handwritten letter patterns that are taught in French schools (e.g., E, T, A, F). Fonts like "Times New Roman" often have serifs that do not appear in handwritten forms. The letter examples we present are in Calibri font so that the reader gets a clear image of the model the child was instructed to reproduce. The letter sequences were presented in font size 72. They were made up of five letters making a total of 14 strokes. A stroke is a motor sequence that is limited by two tangential velocity minima at maximum curvature (Meulenbroek \& van Galen, 1990; Séraphin et al., 2017). For the letters that are made up of straight lines, each line is considered as a stroke (e.g., L has two strokes because it has two straight lines; see Appendix 1). Some letters require pen-lifts such as the horizontal line to finish letter T. These pen-lifts are pointing movements that are produced "in-air" (Rosenblum, 2003). Letter T has two strokes consisting of two straight lines and a pointing movement. In our study, the number of within-letter pen-lifts producing pointing movements was determined by a previous study on upper-case letter production in adults (Séraphin Thibon et 
al., in press; Appendix 1). Other letters are made up of curved lines that are produced by rotation movements (e.g., C). To segment curved lines into strokes, we referred to the stroke definition mentioned above. Following this criteria, letter $\mathrm{C}$ also has two strokes (see Séraphin-Thibon et al., 2017 for an illustration of the stroke segmentation procedure).

To avoid repetition and make the pseudo-words "word-like", half of them had a CVCVC structure (where $\mathrm{C}=$ consonant and $\mathrm{V}=$ vowel) and the other half a VCVCV structure. The production of all the pseudo-words required four between-letter pen lifts that are also pointing movements. Since all the letter sequences were equivalent regarding this point, we constructed our experimental material by counting the within-letter pen lifts. In the Pointing condition, there were eight pseudo-words (Appendix 2). We selected letters that required at least one within-letter pen-lift. To produce these letters correctly, the child had to lift the pen and then place it at a precise spatial location. For example, the pseudo-word FAXET is made out of the following stroke sequence: $F=3$ strokes, $A=3$ strokes, $X=2$ strokes, $E=4$ strokes, $T=2$ strokes. There are six within-letter pointing movements: $F=2, A=1, X=1, E=$ $2, T=1$. None of the letters in the pseudo-words of the Pointing condition contained rotation movements. Many letters of the alphabet require pointing movements. Therefore, for the eight pseudo-words in the Control condition, we selected letter sequences that contained only one or two pointing movements (Appendix 1). In other words, the Pointing and Control conditions differed in the number of within-letter pen-lifts. In the Rotation condition, the eight pseudo-words were made up of letters with curved lines that required at least one rotation movement (Appendix 2). Curved movements were described by Edelman \& Flash (1987) as movements that produce "trajectories consisting of two low-curvature segments connected by a high-curvature one." (pp. 26). For example, the pseudo-word UBOSO contains nine rotations: $\mathrm{U}=1, \mathrm{~B}=2, \mathrm{O}=2, \mathrm{~S}=2, \mathrm{O}=2$. It is noteworthy that letter $\mathrm{O}$ is made up of two 
rotations because it is generally produced with an ovoid shape and is never a perfect circle. In the Control condition we selected letter sequences that contained only one rotation movement (Appendix 1). Therefore, the Rotation and Control conditions differed in the number of rotation movements.

\section{Procedure}

The children were instructed to write the pseudo-words in upper-case letters on a lined sheet of paper that was stuck to the digitizer (spacing between lines $=2.5 \mathrm{~mm}$ ). The digitizer was a Wacom Intuos 3 size A5, with a sampling frequency of $200 \mathrm{~Hz}$ and an accuracy of $0.02 \mathrm{~mm}$. The writing instrument was an Intuos Inking Pen so that the children could see their productions while they were writing on the digitizer. We used the Ductus software (Guinet \& Kandel, 2010) to present the pseudo-words on the screen of the laptop. Before the pseudowords appeared on the screen, there was a fixation point for $1500 \mathrm{~ms}$. We did not give speed instructions but we asked the children to start to "write as soon as you can". The pseudo-word did not disappear from the screen until the child finished writing it. The children first became familiar with the digitizer and the pen by writing their name. There were four practice items. The pseudo-words were randomized across participants. The children did the experiment individually in a quiet room at school. The experiment lasted 25 to 30 minutes.

\section{Data Processing}

The data were analyzed with the analysis module provided by Ductus (Guinet \& Kandel, 2010). The data were smoothed with a Finite Impulse Response filter (Rabiner \& Gold, 1975) 
with a 12-Hz cutoff frequency. Each pseudo-word started with the production of the first letter (pressure $>0$ ) and ended with the final stroke of the fifth letter (pressure $=0$; see Figure 2).

\section{$<$ Figure $2>$}

We examined several measures. Their modulations are indicators of the cognitive load involved in motor execution. Duration concerned the time (ms) the children took to write each letter sequence. It refers to the time the pen touched the surface of the digitizer (pressure $>0$ ). It does not include the time when the pen was in the air. The number of absolute velocity peaks observed for each letter sequence reflects movement fluency during the time the pen touched the surface of the digitizer (pressure > 0) (Meulenbroek \& van Galen, 1989b). Smooth movements have fewer velocity peaks than dysfluent ones. In-air movement duration (ms) refers to the time the pen tip is not touching the digitizer. It corresponds to pressure $=0$ and is an indicator of cognitive load in handwriting production. Dysgraphic children who have difficulties with the mechanics of handwriting have the pen in the air longer than typically developing children (Rosenblum, 2003). Trajectory $(\mathrm{cm})$ refers to the length of the pen tip path on the surface of the digitizer to produce the target letter. Mean velocity refers to the ratio between the trajectory and time $(\mathrm{cm} / \mathrm{s})$. We also measured mean maximal and minimal velocity $(\mathrm{cm} / \mathrm{s})$. These values indicate how fast or slow the child can write while producing the pointing and rotation movements.

\section{Data analysis}

We recorded 2592 data points. There were 4 productions that we could not exploit for technical reasons so we excluded them from the analysis $(0.15 \%$ of the data). When the children made mistakes, did corrections or crossed out their productions, we asked them to start again as many times as necessary. Our analyses only concern the trials without errors. We also excluded the data that exceeded $+/-2.5$ standard deviations from the mean for each 
participant across all sequences for each condition as follows: 69 data points for movement duration (2.66\% of the data), 85 data points for number of velocity peaks (3.27\% of the data), 62 data points for in-air movement duration (2.39\% of the data), 63 data points for trajectory ( $2.4 \%$ of the data), 54 data points for mean velocity ( $2.08 \%$ of the data), 49 data points for maximum velocity $(1.89 \%$ of the data), 60 data points for minimal velocity $(2.31 \%$ of the data).

For the statistical analyses we did a logarithmic transformation on all the data. We then conducted a mixed linear model with the lme4 package provided by R (version RStudio, version 3.0.1; Bates, Maechler \& Bolker, 2011). The model we used included two fixed-effect factors: Age (6, 7, 8, 9 and 10), Condition (Pointing, Rotation, Control) and their interaction. We evaluated the impact of the terms using the function ANOVA of the lmerTest package (Satterthwaite, 1941). The participants were considered as a random effect factor. Multiple comparisons were also conducted with $\mathrm{R}$ using the glht function of the multcomp package and the lsmeans function of the lsmeans package (Russell \& Hervé, 2015). We report the significant differences $(\mathrm{p}<.05)$.

To quantify the changes through development, we calculated for each measure the percentage of increase or decrease from the beginning of the acquisition period (age 6) to the middle of the acquisition period (age 8), and in turn to the end (age 10). For the younger children, this was calculated as $((\mathrm{m} 8-\mathrm{m} 6) / \mathrm{m} 6)^{*} 100$, where $\mathrm{m} 6$ is the mean of the 6 -year-olds and $\mathrm{m} 8$ of the 8 -year-olds for each condition. Likewise, for the older children we did (m10$\mathrm{m} 8) / \mathrm{m} 8) * 100$, where $\mathrm{m} 10$ is the mean for the 10 -year-olds. A positive result means that there was an increase of the measure during the period, whereas a negative result refers to a decrease of the measure. 
Results

Figure 3 presents writing duration (ms), number of velocity peaks, in-air movement duration $(\mathrm{ms})$, and writing trajectory $(\mathrm{cm})$ for the Pointing, Rotation and Control conditions as a function of age.

\section{$<$ Figure $3>$}

Figure 4 presents mean velocity, as well as the maximal and minimal velocity $(\mathrm{cm} / \mathrm{s})$ for the Pointing, Rotation and Control conditions as a function of age.

\section{$<$ Figure $4>$}

\section{Duration}

The effect of condition was significant, $\mathrm{F}(2,2410.93)=38.81, \mathrm{p}<.001$. Writing durations were shorter for Pointing than the Control condition, $\mathrm{z}=-8.65, \mathrm{p}<.001$; they were shorter for Pointing than the Rotation condition, $\mathrm{z}=-6.19, \mathrm{p}<.001$; and they were shorter for Rotation than the Control condition, $\mathrm{z}=-2.47, \mathrm{p}<.05$. Writing duration decreased with age, $\mathrm{F}(4,107.77)=14.00, \mathrm{p}<.001$. The durations were longer for the children of age 7 than age $8, \mathrm{z}=-3.09, \mathrm{p}<.05$. The interaction between the two variables was significant, $\mathrm{F}(8,2410.93)$ $=2.17, \mathrm{p}<.05$. Multiple comparisons revealed that durations were shorter for Pointing than the Control condition at most ages: age $6, \mathrm{t}(2421.33)=-6.37, \mathrm{p}<.001 ;$ age $7, \mathrm{t}(2421.08)=-$ $2.48, \mathrm{p}<.05 ;$ age $8, \mathrm{t}(2421.07)=-5.06, \mathrm{p}<.001 ;$ and age $10, \mathrm{t}(2421.54)=-3.95 \mathrm{p}<.001$. Durations were shorter for Rotation than the Control condition at age 10, $\mathrm{t}(2421.06)=-2.15$, $\mathrm{p}<.05$. Durations were higher for Rotation than Pointing at most ages: age $6, \mathrm{t}(2421.23)=$ 4.54, $\mathrm{p}<.001 ;$ age $7, \mathrm{t}(2421.10)=2.50, \mathrm{p}<.05 ;$ and age $8, \mathrm{t}(2421.11)=3.92, \mathrm{p}<.001$. 
In further analyses we quantified the percentage of duration decrease from the beginning of the writing acquisition period (age 6) to the middle and from the middle to the end of elementary school (age 10). For the younger children, the durations decreased $30 \%$ in the pointing, $30 \%$ in rotation, and $30 \%$ in control conditions. For the older children, the durations decreased $14 \%$ in the pointing, $17 \%$ in rotation, and $15 \%$ in control conditions.

\section{Dysfluency}

The effect of condition was significant, $F(2,2394.86)=173.79, \mathrm{p}<.001$. The Pointing condition produced less dysfluency than the Control $(\mathrm{z}=-6.57, \mathrm{p}<.001)$ or Rotation conditions, $\mathrm{z}=-18.65, \mathrm{p}<.001$. Rotation produced more dysfluency than the Control condition, $\mathrm{z}=12.07, \mathrm{p}<.001$. Dysfluency decreased with age, $\mathrm{F}(4,107.42)=23.26, \mathrm{p}<.001$. Dysfluency decreased from ages 7 to age $8, z=-4.08, p<.001$. The interaction between the two variables was significant, $\mathrm{F}(8,2394.85)=2.46, \mathrm{p}<.05$. Multiple comparisons revealed less dysfluency in the Pointing than Control condition at most ages: age 6, $\mathrm{t}(2405.31)=-5.11$, $\mathrm{p}<.001 ;$ age $8, \mathrm{t}(2405.21)=-2.31, \mathrm{p}<.05 ;$ and age $10, \mathrm{t}(2405.29)=-3.33 \mathrm{p}<.01$. Rotation produced more dysfluency than the Control condition at all ages: age $6, \mathrm{t}(2405.35)=6.96, \mathrm{p}$ $<.001 ;$ age $7, \mathrm{t}(2405.08)=6.40, \mathrm{p}<.001 ;$ age $8, \mathrm{t}(2405.11)=5.38, \mathrm{p}<.001 ;$ age $9, \mathrm{t}(2406.86)$ $=5.28, \mathrm{p}<.001 ;$ and age $10, \mathrm{t}(2405.44)=2.84, \mathrm{p}<.01$. There was more dysfluency in Rotation than Pointing at all ages: age $6, \mathrm{t}(2405.19)=12.10, \mathrm{p}<.001 ;$ age $7, \mathrm{t}(2405.10)=$ $8.39, \mathrm{p}<.001 ;$ age $8, \mathrm{t}(2405.21)=7.68, \mathrm{p}<.001 ;$ age $9, \mathrm{t}(2405.55)=7.09, \mathrm{p}<.001 ;$ and age $10, \mathrm{t}(2405.92)=6.16, \mathrm{p}<.001$. Further analyses revealed that the 6-year-olds were $90 \%$ more dysfluent than the 10-year-olds.

In further analyses we quantified the percentage of dysfluency decrease. For the younger children, the dysfluency decreased $36 \%$ in the pointing, $39 \%$ in rotation, and $38 \%$ in 
control condition. For the older children, the dysfluency decreased $15 \%$ in the pointing, $19 \%$ in rotation, and $12 \%$ in control conditions.

\section{In-air movement duration}

The effect of condition was significant, $F(2,2417.67)=97.22, p<.001$. In-air durations were longer for Pointing than the Control condition, $\mathrm{z}=10.37, \mathrm{p}<.001$; they were longer for Pointing than Rotation, $\mathrm{z}=13.01, \mathrm{p}<.001$; and they were shorter for Rotation than the Control condition, $\mathrm{z}=-2.65, \mathrm{p}<.001$. In-air duration decreased with age, $\mathrm{F}(4,107.13)=36.21$, $\mathrm{p}<.001$. In-air duration decreased from ages 7 to age $8, \mathrm{z}=-4.37, \mathrm{p}<.001$. The interaction between the two variables was significant, $F(8,2417.68)=2.33, p<.05$. Multiple comparisons revealed that in-air durations were longer for Pointing than the Control condition at all ages: age $6, \mathrm{t}(2428.32)=5.04, \mathrm{p}<.001 ;$ age $7, \mathrm{t}(2428.57)=4.56, \mathrm{p}<.001 ;$ age 8 , $\mathrm{t}(2428.17)=4.57, \mathrm{p}<.001 ;$ age $9, \mathrm{t}(2428.35)=5.59, \mathrm{p}<.001 ;$ and age 10, $\mathrm{t}(2429.12)=3.49$, $\mathrm{p}<.01$. In-air durations were shorter for Rotation than the Control condition at age 8, $\mathrm{t}(2427.97)=-2.74, \mathrm{p}<.05$; and age $9, \mathrm{t}(2428.67)=-2.48, \mathrm{p}<.05$. In-air durations were shorter for Rotation than Pointing at all ages: age 6, $\mathrm{t}(2428.21)=-6.11, \mathrm{p}<.001$; age 7 , $\mathrm{t}(2428.56)=-4.68, \mathrm{p}<.001 ;$ age $8, \mathrm{t}(2428.17)=-7.32, \mathrm{p}<.001 ;$ age $9, \mathrm{t}(2428.69)=-8.04, \mathrm{p}<$ $.001 ;$ and age $10, \mathrm{t}(2428.24)=-3.23, \mathrm{p}<.01$.

In further analyses we quantified the percentage decrease of in-air movement duration. For the younger children, the in-air movement duration decreased $42 \%$ in the pointing, $44 \%$ in rotation, and $45 \%$ in control conditions. For the older children, the in-air movement duration decreased $40 \%$ in the pointing, $28 \%$ in rotation, and $34 \%$ in control conditions. 


\section{Trajectory}

The effect of condition was significant, $\mathrm{F}(2,2416.94)=100.98, \mathrm{p}<.001$. Trajectory was shorter for Pointing than the Control condition, $\mathrm{z}=-13.73, \mathrm{p}<.001$; it was shorter for Pointing than Rotation, $\mathrm{z}=-7.50, \mathrm{p}<.001$; and it was shorter for Rotation than the Control condition, $\mathrm{z}$ $=-6.21, \mathrm{p}<.001$. Trajectory increased with age, $\mathrm{F}(4,107.81)=7.47, \mathrm{p}<.001$. Trajectory increased from ages 9 to age $10, \mathrm{z}=2.68, \mathrm{p}<.05$. The interaction between the two variables was significant, $F(8,2416.93)=6.48, \mathrm{p}<.001$. Multiple comparisons revealed that trajectory was shorter for Pointing than the Control condition at age $6, \mathrm{t}(2427.07)=-6.03, \mathrm{p}<.001$; age $8, \mathrm{t}(2427.05)=-8.58, \mathrm{p}<.001 ;$ age $9, \mathrm{t}(2427.06)=-5.61, \mathrm{p}<.001 ;$ and age $10 \mathrm{t}(2427.10)=-$ 9.58, $\mathrm{p}<.001$. Trajectory was shorter for Rotation than the Control condition at most ages: age $6, \mathrm{t}(2427.08)=-4.03, \mathrm{p}<.001 ;$ age $8, \mathrm{t}(2427.13)=-3.89, \mathrm{p}<.001 ;$ age $9, \mathrm{t}(2427.46)=-$ $2.85, \mathrm{p}<.05$; and age 10, $\mathrm{t}(2427.06)=-2.51, \mathrm{p}<.05$. Dysfluency was higher for Rotation than Pointing at age $8, \mathrm{t}(2427.26)=4.65, \mathrm{p}<.001$; age $9, \mathrm{t}(2427.59)=2.69, \mathrm{p}<.05 ;$ and age $10, \mathrm{t}(2427.09)=7.10, \mathrm{p}<.001$.

In further analyses we quantified the percentage of trajectory increase. For the younger children, the trajectory increased $21 \%$ in the pointing, $22 \%$ in rotation, and $27 \%$ in control conditions. For the older children, the trajectory increased $17 \%$ in the pointing, $24 \%$ in rotation, and $18 \%$ in control conditions.

\section{Mean velocity}

The effect of condition was not significant, $p=.30$. Mean velocity increased with age, $F(4$, $107.83)=25.95, \mathrm{p}<.001$. It increased from age 7 to age $8, \mathrm{z}=3.59, \mathrm{p}<.01$; from age 9 to age $10, \mathrm{z}=3.32, \mathrm{p}<.01$. The interaction between the two variables was significant, $\mathrm{F}(4$, $1582.83)=3.62, \mathrm{p}<.01$. Multiple comparisons revealed that mean velocity was higher for 
Pointing than the Rotation condition at age $6, \mathrm{t}(2436.22)=3.21, \mathrm{p}<.01$; for age 7 the differences failed to reach significance, $\mathrm{t}(2436.06)=2.24, \mathrm{p}=.06$.

In further analyses we quantified the percentage of mean velocity increase. For the younger children, the mean velocity increased $76 \%$ in the pointing, $88 \%$ in rotation, and $90 \%$ in control conditions. For the older children, the mean velocity increased $37 \%$ in the pointing, $44 \%$ in rotation, and $45 \%$ in control conditions.

\section{Maximal Velocity}

The effect of condition was significant, $F(2,2430.95)=180.16, p<.001$. There were no significant differences between Pointing and the Control conditions, $p=.9$. Maximal velocity for Pointing and the Control conditions was higher than for Rotation, $\mathrm{z}=16.63, \mathrm{p}<.001$ and $\mathrm{z}$ $=-16.23, \mathrm{p}<.001$, respectively. Maximal velocity increased with age, $\mathrm{F}(4,107.87)=28.13, \mathrm{p}$ $<.001$. It increased from ages 7 to $8, \mathrm{z}=3.60, \mathrm{p}<.01$; and from ages 9 to $10, \mathrm{z}=2.96, \mathrm{p}<$ .05 . The interaction between the two variables was not significant, $\mathrm{p}=.22$.

In further analyses we quantified the percentage of maximal velocity increase. For the younger children, the maximal velocity increased $85 \%$ in the pointing, $92 \%$ in rotation, and $100 \%$ in control conditions. For the older children, the age 10 children presented a $40 \%$ increase in the pointing, $52 \%$ increase in rotation, and $44 \%$ increase in control conditions.

\section{Minimal Velocity}

The effect of condition was significant, $\mathrm{F}(2,2419.87)=898.46, \mathrm{p}<.001$. Minimal velocities were lower for Pointing than the Control condition, $\mathrm{z}=-3.84, \mathrm{p}<.001$; they were lower for Pointing than Rotation, $\mathrm{z}=-36.99, \mathrm{p}<.001$; and they were higher for Rotation than the Control condition, $\mathrm{z}=33.16, \mathrm{p}<.001$. Minimal velocities increased with age, $\mathrm{F}(4,107.63)=$ $16.51, \mathrm{p}<.001$. Minimal velocities increased from ages 7 to age $8, \mathrm{z}=2.77, \mathrm{p}<.05$; and from 
ages 9 to age $10, \mathrm{z}=4.01, \mathrm{p}<.001$. The interaction between the two variables was significant, $\mathrm{F}(8,2419.87)=15.34, \mathrm{p}<.01$. Multiple comparisons revealed that minimal velocities were lower for Pointing than the Control condition at age 9, $\mathrm{t}(2430.20)=-4.35, \mathrm{p}<.001$; and age $10, \mathrm{t}(2430.37)=-2.96, \mathrm{p}<.01$. Minimal velocities were higher for Rotation than the Control condition at all ages: age $6, \mathrm{t}(2430.22)=11.88, \mathrm{p}<.001 ;$ age $7, \mathrm{t}(2430.18)=12.18, \mathrm{p}<.001$; age $8, \mathrm{t}(2430.12)=16.47, \mathrm{p}<.001 ;$ age $9, \mathrm{t}(\mathrm{t}(2430.09)=18.55, \mathrm{p}<.001 ;$ and age 10, $\mathrm{t}(2430.17)=17.45, \mathrm{p}<.001$. Minimal velocities were higher for Rotation than Pointing at all ages: age $6, \mathrm{t}(2430.38)=13.14, \mathrm{p}<.001 ;$ age $7, \mathrm{t}(2430.21)=12.21, \mathrm{p}<.001 ;$ age 8, $\mathrm{t}(2430.06)=16.77, \mathrm{p}<.001 ;$ age $9, \mathrm{t}(2430.08)=22.96, \mathrm{p}<.001 ;$ and age $10, \mathrm{t}(2430.75)=$ $20.32, \mathrm{p}<.001$.

In further analyses we quantified the percentage of minimal velocity increase. For the younger children, the maximal velocity increased $45 \%$ in the pointing, $70 \%$ in rotation, and $38 \%$ in control conditions. For the older children, the minimal velocity increased $35 \%$ in the pointing, $43 \%$ increase in rotation, and $49 \%$ increase in control conditions.

\section{Discussion}

Learning how to write letters is one of the basic skills of writing acquisition. The goal of this study was to examine how letter production is acquired and evolves as children practice writing. By simple observation, we can clearly see that the 26 letters of the alphabet are not all equally easy or difficult to write. Letters requiring many pointing and rotation movements seem to be more cognitively demanding. Pointing movements require in-air movements and, while having the pen in the air, the child has to calculate the precise location within the letter where the pen has to land to start the next stroke. Rotation movements require a different kind of movement control. They are demanding because the curved lines need precision in order to be geometrically regular. This experiment was designed to observe the impact of these kinds 
of movements on letter production. The children wrote pseudo-words in upper-case letters on a digitizer. These letter sequences varied in number of rotation and pointing movements but had the same number of strokes. We observed that pointing and rotation movements affected letter production in different ways. Pointing movements essentially affected writing time by decreasing duration. Rotation movements instead, rendered letter production more dysfluent and affected velocity control. We also observed that the period of automation for letter writing starts at age 8 .

\section{The impact of pointing movements on letter production}

The comparison between the pointing and control conditions indicated that the presence of more pointing movements in the letter sequences systematically decreased movement duration while writing. This was accompanied by a movement duration increase when the hand was in the air. This pattern of results reveals that there is a duration trade-off between movement on surface and movement in-air. It seems as though the on-surface movement is shortened to compensate for the additional time generated by the in-air movement. This suggests there is a sort of tempo for letter production that must be respected somehow, even when producing letters that are cognitively demanding as the ones that require pointing movements. One way of keeping letter duration stable is to increase movement speed, as it is observed in isochronic behavior (Viviani \& Flash, 1995). Globally, the velocity data do not seem to support this idea because the speed differences between the pointing and control conditions did not reach significance. Mean velocity or maximal and minimal speed were equivalent in both conditions. When considering the learning process in two phases, we observed that at the beginning of writing acquisition (i.e., from 6 to 8 years old) mean velocity and maximal speed did not increase at the same pace for the pointing and control conditions. The mean velocity increase was substantial in both conditions (76 and 90\%, respectively). 
However, it was $14 \%$ higher in the control than the pointing condition. Likewise, the evolution of the maximal velocity was $15 \%$ higher in the control than the pointing condition. In the second phase of the learning process, from ages 8 to 10 , mean velocity continued to increase, but in a less pronounced manner (37\% for pointing and $45 \%$ in the control condition). At this stage, the differences between the two conditions were very slight.

The dysfluency data also point to smoother movements in the pointing than the control condition. In the pointing condition the letters were all made up of straight lines whereas in the control condition there were some letters with rotation movements. This could explain the dysfluency differences, but it is unlikely because it would have shown at all ages and not just in three groups (ages 6, 8 and 10). Taken together, it seems that the need for an in-air pointing movement results in a general dysfluency decrease in the first movement that is done on the surface of the digitizer. In line with these results, the on-surface trajectory of the letters for pointing was also shorter than in the control condition. Since the same pattern of results was observed throughout all ages, it seems that this kind of compensatory behavior was already functional from the beginning of the acquisition period.

The general movement duration and dysfluency decrease could be due to the anticipatory character of writing behavior (Orliaguet \& Boë, 1990 for adults; Kandel \& Perret, 2015a for children). In other words, while the children were producing the movement on the surface of the digitizer they were anticipating the production of the in-air movement for pointing. Kandel and Perret (2015a) presented data indicating that at ages 9-10 the children have proficiency in motor anticipation in handwriting. This could explain why the 9 and 10 year-old children produced lower minimal velocity in the pointing condition than the control condition. This is in line with Desmurget et al. (2005) who suggested that pointing movements are not restricted to ballistic movements. Target-reaching requires a correction phase. There is an on-line mechanism that considers the characteristics of the target and 
adapts the movement to be able to reach it. For the 6 and 7 year-old children this mechanism does not seem to be completely efficient yet.

\section{The impact of rotation movements on letter production}

The comparison between the rotation and control conditions revealed that the writing movements to produce curved lines are more dysfluent than the ones to produce straight lines. This dysfluency difference was mainly observed for the children between ages 8 to 10 . The movements for rotation were $7 \%$ more dysfluent than in the control condition. This dysfluency did not systematically increase duration. Globally, mean velocity was equivalent for the rotation and control conditions. However, the analyses indicated that the maximal speed was lower but the minimal speed was systematically higher in the rotation condition. As for duration in pointing movements, there seems to be a trade-off for velocity in rotation movements. This pattern of results suggests that there would be a sort of compensation between maximal and minimal velocity. This idea is reinforced by the fluctuation of minimal and maximal velocity observed during the two phases of writing acquisition. For the younger children, the maximal velocity in the rotation condition increased $92 \%$ and $70 \%$ in minimal velocity. In the control condition, maximal velocity increased $100 \%$ but only $38 \%$ for minimal velocity. So there was a small difference in maximal velocity (8\%) but an important difference in minimal velocity (32\% higher for rotation than the control condition). These important differences were not observed for the older children. The maximal velocity in the rotation condition increased $52 \%$ and $43 \%$ in minimal velocity. In the control condition, maximal and minimal velocity increased $44 \%$ and $49 \%$ respectively. This means that for the 8-10 year old children, the maximal velocity was $8 \%$ higher and the minimal velocity $6 \%$ lower in the rotation than the control condition. This tendency to decrease differences between accelerations and decelerations would render the writing movements more smooth 
and fluent. Reducing velocity variability and rendering it more stable would allow for better movement control when tracing curved lines. Finally, the results also revealed that the trajectory in the rotation condition was globally shorter than the control condition.

In sum, the results point to an increase in dysfluency when producing letters with curved lines. This is also accompanied by a significant decrease in maximal velocity. This suggests that the children limit the ballistic component of movement production and privilege sensory-motor feedback. However, the global tempo of letter production seems to be respected because producing curved letters does not increase movement duration. This suggests a different way of organizing movement production. Producing curved lines generates a decrease in maximal velocity but it does not show globally as a mean velocity difference because minimal and maximal velocity compensate for one another. This decrease could be linked to a functional relation between curvature and movement speed that has been observed extensively in previous research (Binet \& Courtier, 1893; Fitts, 1954; Viviani \& Terzuolo, 1982).

\section{Comparing pointing and rotation movements}

We observed that writing duration was longer for rotation than pointing movements from ages 6 to 8 . At ages 9 and 10 movement duration differences were very slight and no longer reached significance. The inverse pattern was observed for trajectory. At ages 6-7 the trajectories were equivalent for pointing and rotation movements. From 8 to 10 years-old the trajectories in the rotation condition were longer than in the pointing condition. This suggests that there was a general improvement of movement control at age 8. Movement control improved probably because the timing differences disappeared. Movement precision improved because the trajectory for pointing movements decreased. This is in line with previous research indicating that movement automation starts at age 8 (e.g., Mojet, 1991; 
Kandel \& Perret, 2015a, 2015b; Séraphin-Thibon et al., 2017). Furthermore, at the beginning of the acquisition period the letters in the rotation condition seemed to require more movement control than in the pointing condition. Rotation movements seemed to be more cognitively demanding than the ones that are made of sequences of straight lines. This idea is reinforced by the fact that at all ages letter writing was more dysfluent in the rotation than the pointing conditions. Moreover, the maximal velocities were systematically higher in the pointing than the rotation condition. In addition, the minimal velocities were lower for pointing than for rotation. Rotation movements may also be slowed down because curved lines involve friction, both of the hand on the paper and of the pen on the paper, neither of which obtain in the pointing movement.

It is also noteworthy that the differences between pointing and rotation movements were more pronounced for the older children. At the beginning of the learning process, there were only speed differences between the two conditions. Mean velocity, maximum and minimum velocity increases were higher in the rotation than the pointing condition. At the end of Elementary school, pointing and rotation movements not only differed in speed parameters but also on in-air duration and trajectory.

\section{The evolution of letter production}

In this last section we would like to comment the age effect, which was significant for all the measures irrespective of condition. We observed two periods during elementary school. The first one concerned the children through ages 6 to 7 and the second one from 8 to 10. For the younger children there was a decrease in movement duration -on-surface and in-air- and dysfluency. These measures remained stable for the older children. The velocity analyses also point to a turning point when the children are 8 years old. Mean velocity, maximal and 
minimal velocities increased at age 8 , then remained stable from 8 to 9 and then increased again at age 10. These periods of stability suggest that the period of automation for letter writing starts at age 8 . It seems as though the acquisition period extends from ages 6 to 7 . Then, the children become proficient on letter writing at age 8 . There is a period of stabilization from 8 to 9 years-old in which the children practice letter writing to improve proficiency. Full proficiency at age 10 will lead to automation. When the writing movements become fully automatic, writing speed increases. This is the reason why we conducted further analyses to quantify the percentage of increase or decrease of each measure for the younger children (ages 6-8) and the older ones (ages 8-10). Globally, the data revealed that writing automation resulted in a $40 \%$ duration decrease, a $47 \%$ movement dysfluency decrease and a $162 \%$ speed increase.

The pattern of results of the present study are in line with several experiments on writing acquisition (Meulenbroek \& van Galen, 1988, 1989a; Mojet, 1991; Zesiger, Mounoud, \& Hauert, 1993; Kandel \& Perret, 2015a, 2015b; Séraphin-Thibon et al., 2017). There is a clear improvement in movement control at 8 years-old that constitutes the beginning of automation in letter writing. The fact that the control of writing movements starts to become more efficient does not mean that the movements are fully automatic. It does mean that the children have the ability to control their movements and are proficient in letter writing. At this stage of the learning process the children become progressively faster and their movements smoother. Full automation is achieved when the children are able to increase movement velocity and be more precise.

This non-linear evolution could also be related to changes in motor control. Meulenbroek and van Galen $(1986,1988)$ observed that at around ages 8-9 there was a decline in several measures. They accounted for this decline by arguing that the younger children tend to privilege proactive control and ballistic movements. A decline in speed and 
movement fluency at around 8 years old would be due to the introduction of sensory-motor feedback. The objective of this change of movement control strategy would be to render movements more precise. Once the children can control proactive strategies with sensorymotor feedback, there would be an increase in all the measures and the writing movements would be fully automatic. Although this explanation is appealing, it does not fully account for our data because we did not observe a decline in any measure. Moreover, the empirical evidence presented by Mojet (1991) as well as Zesiger (1995) failed to confirm the decline at ages 8-9. We believe that explanations in terms of neuro-motor maturation (see Halsband \& Lange, 2006 for a review; Marcelli \& Cohen 2012) or decrease of cognitive load are more likely. This idea is supported by research on pointing movements (Pellizzer \& Hauert, 1996; Ferrel et al., 2001) indicating quantitative and qualitative changes in movement regulation. Further research should be conducted to gain more understanding on the changes that take place at ages 8-9.

\section{Conclusion}

We observed that the acquisition of letter writing generally occurs between ages 6 and 7 . At 8 years old, the children shift focus to improving movement control. This period marks the beginning of writing automation. Full automation seems to be achieved around age 10, when the children can speed up their movements. This study also sheds some light on the organization of movement control for letter writing. We observed a global tendency to keep stability in the tempo of writing for all the letters irrespective of their individual characteristics and at all ages. Pointing movements were organized in such a way that a decrease of the on surface movement duration compensated for the duration increase generated by the in-air movement. Likewise, we observed that the rotation movements to write letters with curved lines were produced with low maximal velocity but this was 
compensated by a higher minimal velocity. In sum, both pointing and rotation movements require compensatory strategies in specific kinematic variables: pointing movements require a duration trade-off whereas rotation movements present a trade-off on velocity.

Our results find direct application in the classroom for handwriting intervention. We observed that the learning period for pointing and rotation movements extends from 6 to 7 years-old. During this period, the children must understand that this kind of writing movements should respect a precise tempo. This requires regulating duration and speed, which is extremely hard to do because the movements are hard to control. Handwriting intervention should therefore focus on setting the idea of a "tempo" for writing. This can be done by associating hand clapping to specific writing movements. For example, one could imagine a game consisting of writing letters in the air and instructing the children to clap every time they have to start a line in a new position, like in pointing movements. The tempo idea could be extended to music rhythms. Specific songs can "mimic" rotation and pointing movements. Rhythm changes could, for example, illustrate changes in rotation direction (e.g., like the ones in letter S) which are particularly difficult for the age 6 children. From age 8 on, handwriting intervention should be devoted to making the children practice writing gestures as much as they can. Repeated writing activities improve movement control and consolidate compensating strategies for pointing and rotation movements. This leads to an increase in writing speed. This is essential for efficient writing. Efficient writing refers to an essential aspect of writing automation. It involves a compromise between readability and writing speed.

Finally, these finding can be linked to a recurrent debate in educational policies regarding writing style. Do the children learn better how to write in print or cursive style? There is yet no clear-cut answer on this issue. Bara and Morin (2009) for example examined this question and did not reach a convincing conclusion. Perhaps the reason is that print 
requires more pointing movements and cursive handwriting more rotation movements. In other words, both writing styles require the proficiency of compensatory behaviors that start to become automatic around 8 years-old.

\section{Acknowledgments}

We are extremely grateful to the Directrice Académique de l'Education Nationale de l'Isère, school directors and teachers for their precious collaboration in the experimental part of this study. We acknowledge financial support from the Agence Nationale de la Recherche (grant ANR ECRIRE 14-C30- 0013-01) attributed to Sonia Kandel.

\section{References}

Adi-Japha, E., \& Freeman, N. H. (2001). Development of differentiation between writing and drawing systems. Developmental Psychology, 37(1), 101-114.

Ajuriaguerra J. (de), Auzias M., Coumes I., Lavondes-Monod V., Perron R., \& Stambak M. (1964). L'écriture de l'enfant : Vol. 1. L'évolution de l'écriture et ses difficultés. Paris: Delachaux et Niestlé.

Atkinson, J. (1989). New tests of vision screening and asseement in infants and young children. In J. H. French, S. Harel, \& P. Casaer (Eds.), Child neurology and development disabilities (pp. 219-227). Baltimore, MD: Paul H. Brookes Publishi.

Bara, F., \& Bonneton-Botte, N. (2015). Est-il nécessaire d'enseigner le sens du tracé des lettres en capitale d'imprimerie en maternelle? A.N.A.E., 139, 583-592.

Bara, F., \& Morin, M.-F. (2009). Est-il nécessaire d'enseigner l'écriture script en première année ? Les effets du style d'écriture sur le lien lecture/écriture. Nouveaux C@ hiers de La Recherche En Éducation, 12(2), 149. 
Bard, C., Hay, L., \& Fleury, M. (1990). Timing and accuracy of visually directed movements in children: Control of direction and amplitude components. Journal of Experimental Child Psychology, 50(1), 102-118.

Bates, D., Maechler, M., \& Bolker, B. (2011). lme4: Linear mixed-effects models using S4 classes. R package.

Bernstein, N (1967). The coordination and regulation of movement. London: Pergamon Press.

Binet, A., \& Courtier, J. (1893). Sur la vitesse des mouvements graphiques. Revue Philosophique de la France et de l'Etranger, 35, juin, 664-671.

Brenneman K., Massey C., Machado S.F., \& Gelman R., (1996). Young children's plans differ for writing and drawing. Cognitive Development, 11: 397-419.

Bruner, J. S. (1971). The Relevance of Education. New York: Norton.

Chartrel, E., \& Vinter, A. (2004). L'écriture : Une activité longue et complexe à acquérir. Approche Neuropsychologique de l'Apprentissage chez l'Enfant, 78, 174-180

Chartrel, E., \& Vinter, A. (2006). Rôle des informations visuelles dans la production de lettres cursives chez l'enfant et l'adulte, L'Année psychologique, 106, 43-64.

Danna, J., Enderli, F., Athènes, S., \& Zanone, P. G. (2012). Motor coordination dynamics underlying graphic motion in 7- to 11-year-old children. Journal of Experimental Child Psychology, 111(1), 37-51.

Danna, J., \& Velay, J. L. (2015). Basic and supplementary sensory feedback in handwriting. Frontiers in Psychology, 6: 169.

Deiber, M., Wise, S. P., Honda, M., Catalan, M. J., Grafman, J., \& Hallett, M. (1997). Frontal and parietal networks for conditional motor learning: A positron emission tomography study, 977-991. 
Desmurget, M., Turner, R. S., Prablanc, C., Russo, G. S., Alexander, G. E., \& Grafton, S. T. (2005). Updating target location at the end of an orienting saccade affects the characteristics of simple point-to-point movements. Journal of Experimental Psychology. Human Perception and Performance, 31(6), 1510-36.

Dounskaia, N., Van Gemmert, a. W. a, \& Stelmach, G. E. (2000). Interjoint coordination during handwriting-like movements. Experimental Brain Research, 135(1), 127-140.

Edelman, S., \& Flash, T. (1987). A model of handwriting. Biological Cybernetics, 57(1-2), $25-36$.

Feder, K. P., \& Majnemer, A. (2007). Handwriting development, competency, and intervention. Developmental Medicine and Child Neurology, 49(4), 312-317.

Ferrel, C., Bard, C., \& Fleury, M. (2001). Coordination in childhood: Modifications of visuomotor representations in 6- to 11-year-old children. Experimental Brain Research, $138(3), 313-321$.

Fitts, P. M. (1954). The information capacity of the human motor system in controlling the amplitude of movement. Journal of Experimental Psychology, 47(6), 381-391.

Goodnow, J. J., \& Levine, R. A. (1973). “The grammar of action”: In children's sequence and syntax. Cognitive Psychology, 98(4), 82-98.

Goodnow, J.J., (1986). Cognitive and other factors in reading and writing with words and pictures. In: Fisher, M., Wrolstad, D. (Eds.). Towards a new understanding of literacy. New York: Praeger Publishers.

Grossberg, S., \& Paine, R. W. (2000). A neural model of cortico-cerebellar interactions during attentive imitation and predictive learning of sequential handwriting movements. Neural Networks, 13(8-9), 999-1046. 
Guinet, E., \& Kandel, S. (2010). Ductus: A software package for the study of handwriting production. Behavior Research Methods, 42(1), 326-332.

Halsband, U., \& Lange, R. K. (2006). Motor learning in man: a review of functional and clinical studies. Journal of Physiology, 99(4-6), 414-424.

Kandel, S., \& Perret, C. (2015a). How do movements to produce letters become automatic during writing acquisition? Investigating the development of motor anticipation. International Journal of Behavioral Development, 39(2), 113-120.

Kandel, S. \& Perret, C. (2015b). How does the interaction between spelling and motor processes build up during writing acquisition? Cognition, 136, 325-336.

Karmiloff-Smith, A., (1992). Beyond modularity: A developmental perspective in cognitive science. Cambridge, MA: MIT Press.

Kelso, J. S. (1982). The process approach to understanding human motor behavior: An introduction. Human motor behavior: An introduction, (pp. 3-19). Hillsdale, NJ: Lawrence Erlbaum.

Klein, S., Guiltner, V., Sollereder, P., \& Cui, Y. (2011). Relationships between fine-motor, visual-motor, and visual perception scores and handwriting legibility and speed. Physical \& Occupational Therapy in Pediatrics, 31(1), 103-114.

Lavine, L.O. (1977). Differentation of letter-like forms in pre-reading children. Developmental Psychology, 13, 89-94.

Marcelli, D. \& Cohen, D. (2012). Enfance et Psychopathologie, (9e éd). Paris: Masson.

Marquardt, C., Gentz, W., \& Mai, N. (1996). On the role of vision in skilled handwriting. In Simner, ML, Leedham, G,. \& Thomassen, A.J.W.M. (Eds.) Handwriting and drawing research. (pp. 87-97). Amsterdam: IOS Press. 
Marquardt, C., Gentz, W., \& Mai, N. (1999). Visual control of automated handwriting movements. Experimental Brain Research, 128(1-2), 224-228.

Marr, D., Cermak, S., Cohn, E. S., \& Henderson, A. (2003). Fine motor activities in Head Start and kindergarten classrooms. American Journal of Occupational Therapy, 57(5), $550-557$.

Meulenbroek, R. G. J., \& van Galen, G. P. (1986). Movement analysis of repetitive behaviour of first, second and third grade primary school children. In H. S. Kao, G. P. Van Galen \& R. Hoosain (Eds.), Graphonomics: Contemporary research in handwriting (pp. 71-92). Amsterdam: North Holland

Meulenbroek, R. G. J., \& van Galen, G. P. (1988). The Acquisition of Skilled Handwriting: Discontinuous Trends in Kinematic Variables. Advances in Psychology, 55, 273-281.

Meulenbroek, R.G.J., \& van Galen, G.P. (1989a). The production of connecting strokes in cursive writing: Developing co-articulation in 8 to 12 year-old children. In R Plamondon, C.Y. Suen \& M.L. Simner (Eds.), Computer recognition and human production of handwriting (pp. 105-118). Singapore: World Scientific.

Meulenbroek R.G.J.; Van Galen G.P. (1989b). Variations in cursive handwriting performance as a function of handedness hand posture and gender. Journal of Human Movement Studies, 16(5): 239-254.

Meulenbroek, R. G., \& Van Galen, G. P. (1990). Perceptual-motor complexity of printed and cursive letters. Journal of Experimental Education, 58(2), 95-110.

Meulenbroek, R. G. J., Vinter, a, \& Mounoud, P. (1993). Development of the start-rotation principle in circle production. British Journal of Developmental Psychology, 11, 307-320.

Ministère de l'Education Nationale (2015). EduSCOL. L'écriture à la Maternelle: la forme des lettres. Ressources maternelles, graphisme et écriture. [Online] 
http://media.education.gouv.fr/file/Ecriture/43/5/Ress_c1_Ecriture_formelettres_456435.pdf.

Mojet, W. (1991). Characteristics of developing handwriting skills in elementary education. In J Wann, A Wing, N Sovik (Eds.), Development of graphic skills (pp. 53-75). London: Academic Press.

Olive, T., \& Piolat, A. (2002). Suppressing visual feedback in written composition: Effects on processing demands and coordination of the writing processes. International Journal of Psychology, 37(4), 209-218.

Orliaguet, J-P, Boë, L-J. (1990). Régulation temporelle des mouvements d'écriture en fonction des contraintes spatiales. In: V. Nougier and J.P. Blanchi (eds.), Pratiques sportives et modélisation du geste (pp. 163-177). Grenoble: Grenoble Sciences.

Pellizzer, G., \& Hauert, C. A. (1996). Visuo-manual aiming movements in 6- to 10-year-Old children: evidence for an asymmetric and asynchronous development of information processes. Brain and Cognition, 30(30), 175-193.

Petersen, S. E., Corbetta, M., Miezin, F. M., \& Shulman, G. L. (1994). PET studies of parietal involvement in spatial attention: comparison of different task types. Canadian Journal of Experimental Psychology, 48(2), 319.

Rabiner, L. R., \& Gold, B. (1975). Theory and application of digital signal processing. Englewood Cliffs, NJ: Prentice Hall.

Rosenblum, S. (2003). The in air phenomenon: Temporal and spatial correlates of the handwriting process. Perceptual and Motor Skills, 96(3), 933.

Rueckriegel, S. M., Blankenburg, F., Burghardt, R., Ehrlich, S., Henze, G., Mergl, R., \& Hernáiz Driever, P. (2008). Influence of age and movement complexity on kinematic hand 
movement parameters in childhood and adolescence. International Journal of Developmental Neuroscience, 26(7), 655-663.

Russell, V. L., \& Hervé, M. (2015). 1smeans: Least-Squares Means. R package version 2.16. [On line] http://CRAN.R-project.org/package=lsmeans.

Santangelo, T., \& Graham, S. (2016). A comprehensive meta-analysis of handwriting instruction. Educational Psychology Review, 28(2), 225-265.

Satterthwaite, F. E. (1941). Synthesis of variance. Psychometrika, 6(5), 309-316.

Séraphin Thibon, L., Gerber, S. \& Kandel, S. (in press). Analyzing variability in upper-case letter production in adults. In C. Perret \& T. Olive (eds.). Studies in Writing. NL: Brill Editions.

Séraphin-Thibon, L., Gerber, S., Kandel, S. (2017, published on-line). Learning how to write letters: The elaboration of motor programs for handwriting movement automation. Acta Psychologica.

Shadmehr, R., \& Mussa-Ivaldi, F. A. (1994). Adaptive representation of dynamics during learning of a motor task. The Journal of Neuroscience, 14(5), 3208-3224.

Teulings, H.L. (1996). Handwriting movement control. In S.W. Keele \& H. Heuer (Eds.). Handbook of perception and action, Vol.2: Motor Skills (pp. 561-613). London: Academic Press.

Thomassen, A. J., \& Teulings, H. L. (1985). Time, size and shape in handwriting: Exploring spatio-temporal relationships at different levels. In Time, mind, and behavior (pp. 253263). Springer Berlin Heidelberg.

Tolchinsky-Landsmann, L, (2003). The cradle of culture and what children know about writing and numbers before being taught. Hillsdale, NJ: Lawrence Erlbaum Associates. 
Van Sommers, P. (1984). Drawing and cognition: Descriptive and experimental studies of graphic production processes. Cambridge, UK: Cambridge University Press.

Vinter, A. (1994). Hierarchy between graphic production rules in the drawing of elementary figures. In Faure, C., Keuss, P., Lorette, G., \& Vinter, A. (Eds.), Advances in Handwriting and Drawing: a multidisciplinary approach (pp.275-292). Paris: Europia.

Viviani, P., \& Flash, T. (1995). Minimum-jerk, two-thirds power law, and isochrony: converging approaches to movement planning. Journal of Experimental Psychology: Human Perception and Performance, 21(1), 32.

Viviani, P., \& Schneider, R. (1991). A developmental study of the relationship between geometry and kinematics in drawing movements. Journal of Experimental Psychology: Human Perception and Performance, 17(1), 198-218.

Viviani, P., \& Terzuolo, C. (1982). Trajectory determines movement dynamics. Neuroscience, $7(2), 431-437$.

Wann, J. P. (1986). Handwriting disturbances: Developmental trends. In H.T.A. Whiting \& M.G. Wade (Eds.), Themes in motor development (pp. 207-226). Dordrecht: Nijhoff.

Wolpert, D. M., Ghahramani, Z., \& Jordan, M. I. (1995). An internal model for sensorimotor integration. Science, 269, 1880-1882.

Zesiger, P. (1995). Ecrire : Approches cognitive, neuropsychologique et développementale. Paris : Presse Universitaires de France.

Zesiger, P., Mounoud, P., \& Hauert, C. A. (1993). Effects of lexicality and trigram frequency on handwriting production in children and adults. Acta Psychologica, 82(1-3), 353-365. 
Figure 1

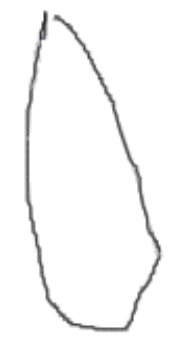


Figure 2
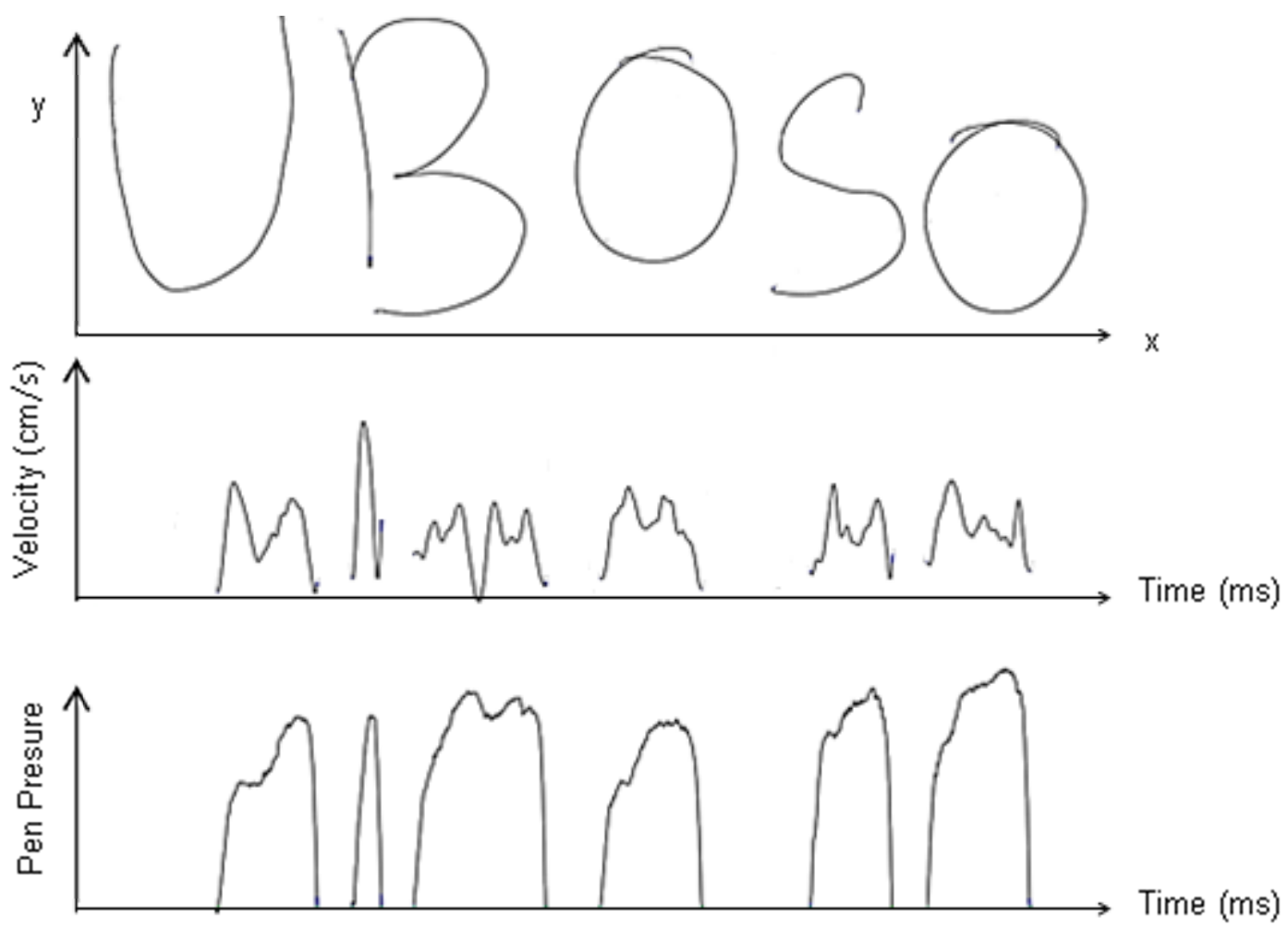
Figure 3
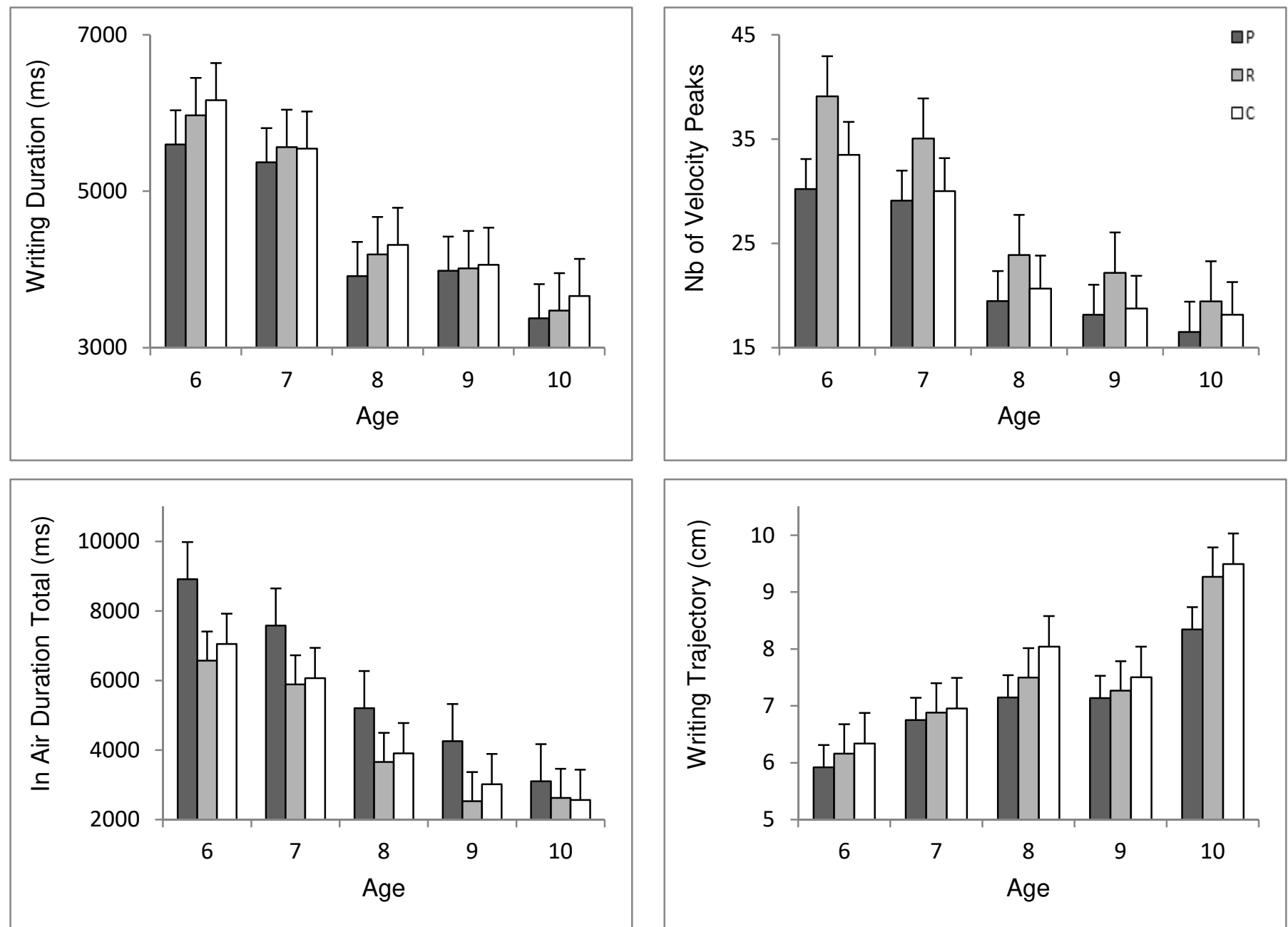
Figure 4
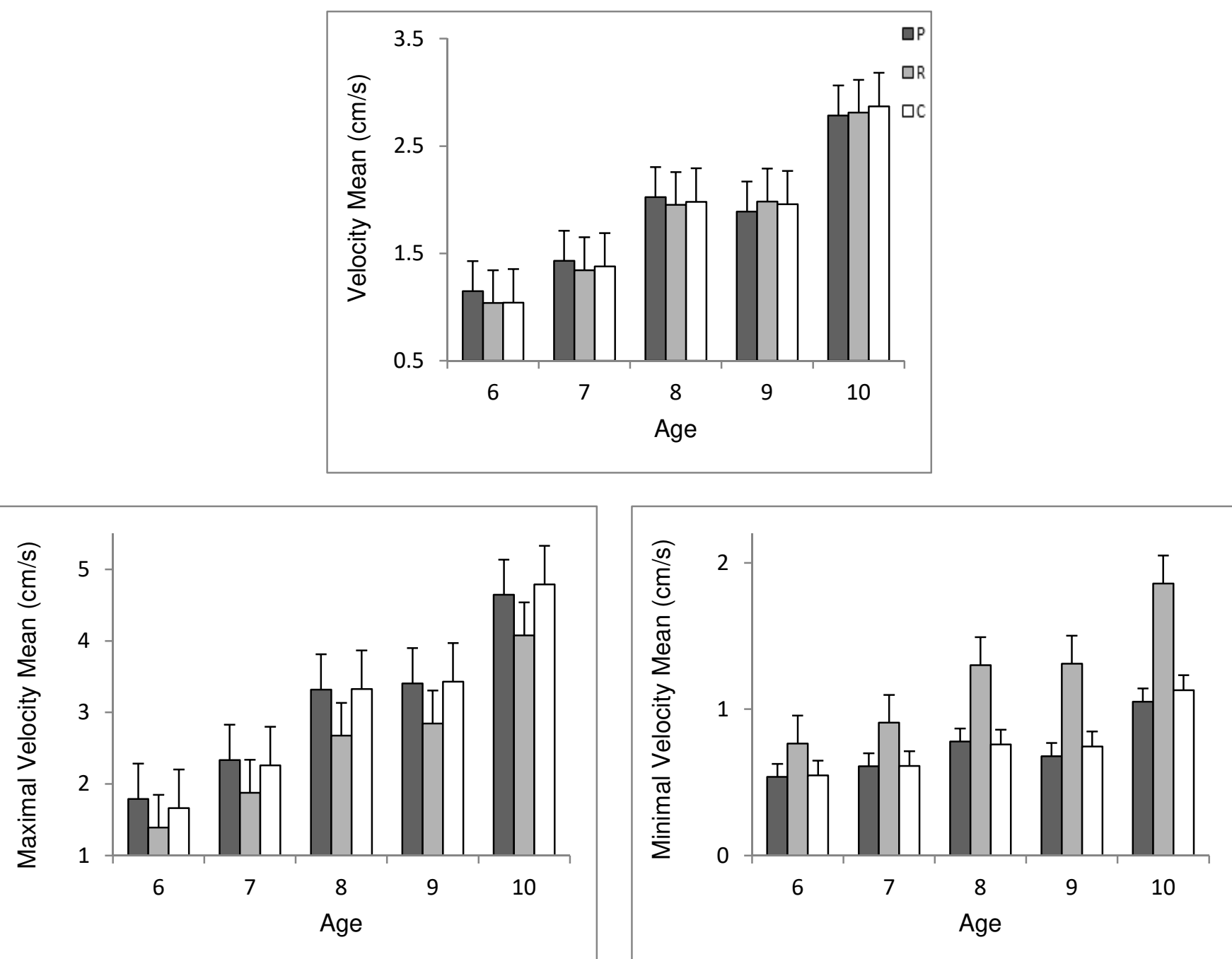
Figure Captions

Figure 1. Examples of upper-case letters produced by a 6 year-old child at the beginning of $1^{\text {st }}$ grade. Left: Illustration of difficulties with pointing movements required for producing letter

T. Right: Illustration of difficulties with rotation movements required for producing letter $\mathrm{O}$.

Figure 2. Upper part: Production of pseudo-word UBOSO by a child of age 7. Central part: Velocity as a function of time. Lower part: Pen pressure as a function of time.

Figure 3. Mean writing duration (ms), number of velocity peaks, in-air movement duration (ms), and writing trajectory $(\mathrm{cm})$ for the Pointing, Rotation and Control conditions as a function of age (ages 6 to 10). Bars indicate standard error.

Figure 4. Mean velocity, maximal and minimal velocity $(\mathrm{cm} / \mathrm{s})$ for the Pointing, Rotation and Control conditions as a function of age (ages 6 to 10). Bars indicate standard error. 